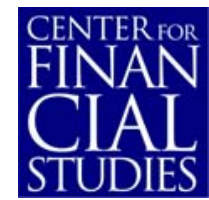

No. $2008 / 29$

Does Trade Integration Alter

Monetary Policy Transmission?

Tobias J. Cwik, Gernot J. Müller, and Maik $\mathrm{H}$. Wolters 


\section{Center for Financial Studies}

The Center for Financial Studies is a nonprofit research organization, supported by an association of more than 120 banks, insurance companies, industrial corporations and public institutions. Established in 1968 and closely affiliated with the University of Frankfurt, it provides a strong link between the financial community and academia.

The CFS Working Paper Series presents the result of scientific research on selected topics in the field of money, banking and finance. The authors were either participants in the Center's Research Fellow Program or members of one of the Center's Research Projects.

If you would like to know more about the Center for Financial Studies, please let us know of your interest.

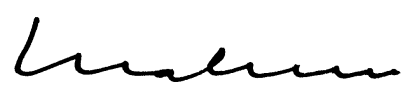

Prof. Dr. Jan Pieter Krahnen

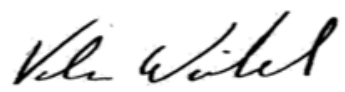

Prof. Volker Wieland, Ph.D. 


\title{
Does Trade Integration Alter Monetary Policy Transmission?*
}

\author{
Tobias J. Cwik ${ }^{1}$, Gernot J. Müller ${ }^{2}$, \\ and Maik H. Wolters ${ }^{3}$
}

\author{
August 18, 2008
}

\begin{abstract}
:
This paper explores the role of trade integration-or openness-for monetary policy transmission in a medium-scale New Keynesian model. Allowing for strategic complementarities in price-setting, we highlight a new dimension of the exchange rate channel by which monetary policy directly impacts domestic inflation. Although the strength of this effect increases with economic openness, it also requires that import prices respond to exchange rate changes. In this case domestic producers find it optimal to adjust their prices to exchange rate changes which alter the domestic currency price of their foreign competitors. We pin down key parameters of the model by matching impulse responses obtained from a vector autoregression on U.S. time series relative to an aggregate of industrialized countries. While we find evidence for strong complementarities, exchange rate pass-through is limited. Openness has therefore little bearing on monetary transmission in the estimated model.
\end{abstract}

JEL Classification: F41, F42, E52

Keywords: Monetary Policy Transmission, Open Economy, Trade Integration, Exchange Rate Channel, Strategic Complementarity, Exchange Rate Pass-Through

\footnotetext{
* We thank participants of 39th Konstanz Seminar on Monetary Theory and Policy and our discussant Boris Hofmann for very helpful comments. In addition we gratefully acknowledge very helpful discussions with Zeno Enders, Philip Jung, Keith Kuester and Volker Wieland. The usual disclaimer applies. Please address correspondence to cwik@wiwi.uni-frankfurt.de, gernot.mueller@wiwi.unifrankfurt.de or wolters@wiwi.uni-frankfurt.de.

1 Goethe University Frankfurt, E-mail: cwik@wiwi.uni-frankfurt.de

2 Goethe University Frankfurt and CFS, E-mail: muellerg@wiwi.uni-frankfurt.de

3 Goethe University Frankfurt, E-mail: wolters@wiwi.uni-frankfurt.de
} 


\section{Introduction}

Recent research on the monetary transmission mechanism has focused on the quantitative performance of dynamic stochastic general equilibrium (DSGE) models. Specifically, interest has centered on their ability to account for the dynamic effects of monetary policy shocks as apparent from estimated vector autoregression (VAR) models. In a seminal study, Christiano, Eichenbaum, and Evans (2005) show that a medium scale New Keynesian model mimics quite closely the VAR-responses to a monetary policy shock of as many as nine variables. This result is obtained while abstracting from external trade altogether. Taken at face value, it suggests that trade integration, or openness, plays no important role for monetary policy transmission - at least as far as a large open economy such as the U.S. is concerned. ${ }^{1}$

There is, however, a secular trend in trade integration, suggesting that economies are becoming considerably more open over time. In the U.S., imports, as a fraction of GDP, have risen from about 6 percent in 1973 to 16 percent to date. In fact, as this trend has been accelerating over the last decade, some observers have identified increasing trade integration as an important manifestation of globalization. ${ }^{2}$ In this paper, we investigate more systematically the role of trade integration for monetary policy transmission, where we measure trade integration by the import-to-GDP ratio. Specifically, we assess how increasing openness alters quantitatively the effects of monetary policy shocks on domestic (i.e. producer price) inflation and domestic absorption. We focus on these variables, because they are well defined in closed economy models as well.

Taking an analytical perspective, earlier work by Clarida, Galí, and Gertler (2001) and Galí and Monacelli (2005) has stressed the similarity between open and closed economy versions of the New Keynesian baseline model. In fact, apart from being a source of additional shocks, 'openness' merely alters some of the reduced-form coefficients of the canonical representation of the model which is, in fact, shown to be isomorphic in closed and open economies. More recently, Erceg, Gust, and López-Salido (2007) have shown that the difference between closed and open economies in this class of models hinges on the relative size of the intertemporal elasticity of substitution and the trade price elasticity. Moreover, these authors argue that-for reasonable calibrations-increasing openness is unlikely to alter the transmission of domestic shocks, monetary policy shocks inclusive, in a quantitatively important way.

\footnotetext{
${ }^{1}$ Other studies which employ this approach find similarly satisfactory results for variants of the New Keynesian model. Rotemberg and Woodford (1997), Amato and Laubach (2003), Bovin and Giannoni (2006) and Meier and Müller (2006) are examples. These studies also assume counterfactually closed economy models. Clearly, other studies have explored the empirical performance of open economy DSGE models; yet these studies have typically not been particularly concerned with monetary transmission, see, e.g., Lubik and Schorfheide (2006) and Adolfson, Laséen, Lindé, and Villani (2007).

${ }^{2}$ The consequences of globalization for monetary policy are widely discussed both in academia and among policy makers. Most commentators, taking a fairly general perspective, have argued that globalization does not fundamentally affect the central bank's ability to control the economy, see, e.g., Mishkin (2007) and Bernanke (2007). Changes brought about by globalization may nevertheless require, as Yellen (2006) puts it, "some recalibration of policy responses".
} 
However, taking up the question within the New Keynesian baseline model twists the analysis towards finding no effect of openness. A key assumption underlying the derivation of the New Keynesian Phillips curve and, hence, its isomorphism in closed and open economies, is that the demand functions faced by intermediate goods firms are characterized by a constant elasticity of substitution. This, in turn, implies that the desired markup is independent of the price of competitors, i.e. there are no strategic complementarities in price setting. Such complementarities arise under a more general formulation of the demand functions, or, rather, the underlying aggregation technology. In this case, the isomorphism of the New Keynesian Phillips curve in closed and open economies breaks down. Intuitively, strategic complementarities arise not only with respect to domestic, but also with respect to foreign competitors. Hence, the domestic currency price charged by foreign competitors enters the decision problem of domestic firms and eventually the New Keynesian Phillips curve. Recently, Guerrieri, Gust, and López-Salido (2008) have highlighted the importance of this mechanism in accounting for inflation dynamics. ${ }^{3}$

In this paper, we take price-setting complementarities into account when exploring the role of openness for monetary transmission. As a result, a new dimension of the exchange rate channel emerges. Traditionally, monetary policy is thought to directly impact CPI-inflation and to indirectly impact domestic inflation via the exchange rate, where the latter effect comes about through changes in demand induced by 'expenditure-switching'. With strategic price-setting complementarities, changes in the exchange rate, which alter the domestic currency prices charged by foreign competitors, directly impact domestic inflation. The importance of this effect increases with i) the extent of strategic complementarities in price-setting; ii) the openness of an economy and iii) the amount of exchange rate pass-through.

Our analysis is based on a medium-scale two-country DSGE model. It features an aggregation technology for the production of final goods which gives rise to strategic complementarities in pricesetting; in addition, the aggregation technology determines trade integration by giving unequal weight to domestically produced and imported intermediate goods. The model also features a number of frictions which the literature has found to increase the empirical success of this class of models; notably, we allow exchange rate pass-through to be limited in the short-run. Overall, the model structure is rich enough to provide a quantitatively realistic account of the monetary transmission mechanism such as to allow us to study the quantitative implications of trade integration on monetary transmission.

As a benchmark, we compute impulse responses to a monetary policy shock within a VAR model estimated on quarterly time series data for the U.S. relative to an aggregate of industrialized countries. In addition to standard 'closed-economy' variables, the VAR model also includes CPI-inflation as well as U.S. net exports. We treat the impulse responses as a characterization of the actual monetary

\footnotetext{
${ }^{3}$ Specifically, they estimate the resulting variant of the New Keynesian Phillips curve on the basis of single equation techniques. Importantly, in contrast to our analysis, they assume that all firms engage in local currency pricing.
} 
transmission mechanism and estimate the structural parameters of the DSGE model employing the minimum distance estimation strategy suggested by Rotemberg and Woodford (1997) and Christiano et al. (2005). To avoid identification problems we fix several parameter values prior to the estimation, most notably the degree of openness which we assume to be 12 percent, i.e. the average import-GDPratio of the U.S. in our sample. We estimate the values of nine parameters and find that the estimated model is able to replicate the VAR evidence fairly well for plausible parameter values. Three estimates are particularly noteworthy: a low value for the trade price elasticity, strong complementarities in price-setting and limited exchange rate pass-through.

In order to explore the role of openness, we compute the effects of a monetary policy shock in an economy that is approximately closed and an economy where imports account for 40 percent of GDP. Relative to the baseline economy, there is hardly any difference in the responses of domestic inflation and absorption in these counterfactual economies. Two reasons are key for this result. First, the estimated value for the trade price elasticity is close to intertemporal elasticity of substitution, which, according to the results reported by Erceg et al. (2007), prevents openness from altering the dynamics of the New Keynesian baseline model. Second, as exchange rate pass-through is limited, the exchange rate channel is prevented from operating in a quantitatively important way. We find, however, that strategic complementarities in price-setting would, in principle, constitute an important channel through which openness impacts monetary transmission. Specifically, if we increase the exchange rate pass-through from an estimated value of 12 percent to 40 percent, openness has sizeable effects. In this case, moving from the closed to the very open economy increases the effects of a monetary policy shock on domestic inflation by some 25 percent. As an implication for monetary policy, we stress that the joint evolution of trade integration as well as exchange rate pass-through should be monitored closely.

The remainder of this paper is organized as follows. In section 2 we introduce the details of the model economy. Section 3 presents time series evidence from the estimated VAR model and discusses the estimation of the DSGE model. In section 4, we take a closer look at the role of trade integration for monetary transmission. Section 5 concludes.

\section{Model}

In this section we develop a two-country DSGE model to study monetary policy transmission in open economies. Most of the model features are standard and familiar from so-called medium scale DSGE models as put forward, for instance, in Christiano et al. (2005) or Smets and Wouters (2005) in a closed economy context. ${ }^{4}$ There is a representative household in each country owning the capital

\footnotetext{
${ }^{4}$ In setting up the model we also draw on earlier work by Chari, Kehoe, and McGrattan (2002), Kollmann (2002), Galí and Monacelli (2005) and Corsetti and Pesenti (2005), among others.
} 
stock which is rented together with labor services to intermediate goods producers on a period-byperiod basis. Adjusting the level of investment is costly. International financial markets are assumed to be complete.

We assume that in each country there is a continuum of intermediate good producers operating under monopolistic competition and being constrained in price setting à la Calvo. A fraction of these firms invoices exports in their own currency. Using common terminology, these firms are engaging in 'producer currency pricing', or 'PCP' for short. The remaining firms are engaging in 'local currency pricing', or 'LCP', by invoicing domestic sales and exports in the currency of domestic and foreign buyers, respectively. A key aspect of monetary transmission in open economies is the extent of exchange rate pass-through. In our setup it will be smaller, the more pervasive LCP for any given degree of price rigidity. ${ }^{5}$

In each country final goods firms combine domestic and imported intermediate goods to provide households with final goods used for consumption and investment purposes. The aggregation technology employed by final goods firms may imply unequal weights of domestic and imported intermediates in the production of final goods - thereby determining the degree of openness. In addition, the aggregation technology induces demand functions for intermediate goods which are characterized by a non-constant price elasticity of substitution (NCES). Such an aggregation technology has recently been advocated by Gust et al. (2006), and Guerrieri et al. (2008) in an open economy context. Importantly, it induces strategic complementarities in price-setting among intermediate good firms not only with respect to domestic, but also with respect to foreign competitors. ${ }^{6}$

In the following we give a formal exposition of the model, discussing in turn the problems of final goods firms, intermediate good firms, and the representative household. We close the model with a feedback rule to characterize monetary policy. As both countries are symmetric, of equal size, and have isomorphic structures, we focus on the domestic economy, i.e. on the 'home' country. When necessary we refer to foreign variables by means of a star superscript.

\subsection{Final goods firms}

Final goods are composites of intermediate goods produced by a continuum of monopolistic competitive firms in both countries. We use $j \in[0,1]$ to index intermediate good firms as well as their products and prices. Final goods firms operate under perfect competition and purchase domestically

\footnotetext{
${ }^{5}$ See Bergin (2006) for a similar formulation, Betts and Devereux $(1996,2000)$ for early contributions and Obstfeld and Rogoff (2000) for a critical discussion. Note that in the present model nominal rigidities are critical for limiting the extent of exchange rate pass-through. Corsetti and Dedola (2005) and Gust, Leduc, and Vigfusson (2006), in contrast, provide real models of limited exchange rate pass-through.

${ }^{6}$ The original closed economy formulation goes back to Dotsey and King (2005) or, more generally, to Kimball (1995). Sbordone (2007) uses a similar technology when discussing the consequences of firm entry for the slope of the New Keynesian Phillips curve. While Gust et al. (2006) and Guerrieri et al. (2008) focus on pass-through and inflation dynamics, respectively, we explore the implications for monetary transmission.
} 
produced intermediate goods, $A_{t}(j)$, as well as imported intermediate goods, $B_{t}(j)$. Final goods, $F_{t}$ are not traded across countries, but are used for domestic consumption, $C_{t}$, investment, $I_{t}$, and government spending, $G_{t}$. In each period, market clearing requires that $F_{t}=C_{t}+X_{t}+G_{t}$.

Letting $P_{t}^{A}(j)$ denote the domestic price of a domestically produced intermediate good and $P_{t}^{B}(j)$ the domestic price of an imported intermediate good, the problem of the representative final goods firm is to produce $F_{t}$ while minimizing expenditures given by

$$
\int_{0}^{1} P_{t}^{A}(j) A_{t}(j) d j+\int_{0}^{1} P_{t}^{B}(j) B_{t}(j) d j
$$

subject to

$$
\left[V_{D t}^{\frac{\sigma-1}{\sigma}}+V_{M t}^{\frac{\sigma-1}{\sigma}}\right]^{\frac{\sigma}{\sigma-1}}-\left[\frac{1}{(1+\eta) v}-1\right]=1
$$

where $V_{D t}$ and $V_{M t}$ are defined as follows

$$
\begin{gathered}
V_{D t}=\int_{0}^{1} \omega^{\frac{\sigma}{\sigma-1}} \frac{1}{(1+\eta) v}\left[\frac{(1+\eta)}{\omega} \frac{A_{t}(j)}{F_{t}}-\eta\right]^{v} d j \\
V_{M t}=\int_{0}^{1}(1-\omega)^{\frac{\sigma}{\sigma-1}} \frac{1}{(1+\eta) v}\left[\frac{(1+\eta)}{(1-\omega)} \frac{B_{t}(j)}{F_{t}}-\eta\right]^{v} d j .
\end{gathered}
$$

Our aggregation technology given by (2), (3) and (4) follows Gust et al. (2006) closely. A few remarks concerning key parameters are in order. The trade price elasticity, i.e. the elasticity which measures the extent of substitution from goods produced at home to those produced abroad for a given change in relative prices, is a key parameter for the international transmission mechanism. In our setup it is a function of several parameters and given by

$$
\tilde{\sigma}=\frac{-\sigma}{(\sigma(v-1)-v)(1+\eta)} .
$$

The elasticity of substitution between goods produced within the same country is generally time varying. In steady state it is constant and given by

$$
\epsilon=\frac{1}{1-v} \frac{1}{1+\eta} .
$$

The parameter $\eta$ plays a crucial role for both elasticities. It provides a measure of how strongly our setup deviates from the special case where the elasticity of substitution is constant (CES), which is nested in our model for $\eta=0$. Finally, the parameter $\omega$ measures the weight of domestically produced goods in final goods in steady state. $1-\omega$ measures the fraction of imports in final goods in steady state and thus corresponds to the import-GDP-ratio.

Optimization behavior of domestic and foreign final goods firms gives rise to demand functions for domestically produced intermediate goods

$$
\begin{aligned}
& A_{t}(j)=\frac{\omega}{1+\eta}\left[\left(\frac{P_{t}^{A}(j)}{P_{t}^{A}}\right)^{\frac{1}{v-1}}\left(\frac{P_{t}^{A}}{\Gamma_{t}}\right)^{\frac{\sigma}{\sigma(v-1)-v}}+\eta\right] F_{t}, \\
& A_{t}^{*}(j)=\frac{1-\omega}{1+\eta}\left[\left(\frac{P_{t}^{A *}(j)}{P_{t}^{A *}}\right)^{\frac{1}{v-1}}\left(\frac{P_{t}^{A *}}{\Gamma_{t}^{*}}\right)^{\frac{\sigma}{\sigma(v-1)-v}}+\eta\right] F_{t}^{*},
\end{aligned}
$$


where $\Gamma_{t}$ is a price index defined below. Global demand for a generic good $j$ is then given by

$$
Y_{t}(j)=A_{t}(j)+A_{t}^{*}(j)
$$

Note that the demand function includes a linear term if $\eta \neq 0$. As a result, price elasticities of demand and the desired markup of intermediate goods firms will be time-varying, or, in other words, price-setting behavior at the level of intermediate goods firms is characterized by strategic complementarities.

The optimization problem of final goods firm implicitly defines price indices. For further reference, it is useful to explicitly distinguish between the prices charged by LCP and PCP-firms. Therefore, let $P_{t}^{A, P C P}(j)$ and $P_{t}^{A, L C P}(j)$ denote the domestic price charged by a domestic intermediate goods firm engaged in PCP and LCP, respectively. Letting $\alpha \in[0,1]$ be the fraction of LCP-firms and $(1-\alpha)$ the fraction of PCP-firms, the domestic producer price index $P_{t}^{A}$ and the import prices index $P_{t}^{B}$ are given by the following expressions:

$$
\begin{aligned}
P_{t}^{A} & =\left(\int_{0}^{\alpha} P_{t}^{A, L C P}(j)^{\frac{v}{v-1}} d j+\int_{\alpha}^{1} P_{t}^{A, P C P}(j)^{\frac{v}{v-1}} d j\right)^{\frac{v-1}{v}}, \\
P_{t}^{B} & =\left(\int_{0}^{\alpha} P_{t}^{B, L C P}(j)^{\frac{v}{v-1}} d j+\int_{\alpha}^{1} P_{t}^{B, P C P}(j)^{\frac{v}{v-1}} d j\right)^{\frac{v-1}{v}} .
\end{aligned}
$$

The price index for final goods is given by

$$
\begin{aligned}
P_{t} & =\frac{1}{1+\eta} \Gamma_{t}+\frac{\eta}{1+\eta} \omega\left(\int_{0}^{\alpha} P_{t}^{A, L C P}(j) d j+\int_{\alpha}^{1} P_{t}^{A, P C P}(j) d j\right) \\
& +\frac{\eta}{1+\eta}(1-\omega)\left(\int_{0}^{\alpha} P_{t}^{B, L C P}(j) d j+\int_{\alpha}^{1} P_{t}^{B, P C P}(j) d j\right),
\end{aligned}
$$

where

$$
\Gamma_{t}=\left[\omega\left(P_{t}^{A}\right)^{\frac{(\sigma-1) v}{\sigma(v-1)-v}}+(1-\omega)\left(P_{t}^{B}\right)^{\frac{(\sigma-1) v}{\sigma(v-1)-v}}\right]^{\frac{\sigma(v-1)-v}{(\sigma-1) v}} .
$$

Finally, letting $S_{t}$ denote the nominal exchange rate and assuming that the law of one price holds for PCP-firms, we obtain the following relationships:

$$
P_{t}^{B, P C P}(j)=S_{t} P_{t}^{B, P C P *}(j) ; \quad P_{t}^{A, P C P}(j)=S_{t} P_{t}^{A, P C P *}(j) .
$$

\subsection{Intermediate good firms}

The production of intermediate goods, $Y_{t}(j)$, is governed by a Cobb-Douglas production function

$$
Y_{t}(j)=K_{t}(j)^{\theta} H_{t}(j)^{1-\theta}
$$

where $H_{t}(j)$ and $K_{t}(j)$ denote labor and capital employed by firm $j$. Letting $W_{t}$ and $R_{t}$ denote the nominal wage rate and the rental rate of capital, respectively, minimizing costs implies for (nominal) 
marginal costs

$$
M C_{t}(j)=\frac{W_{t} H_{t}(j)}{(1-\theta) Y_{t}(j)}=\frac{R_{t} K_{t}(j)}{\theta Y_{t}(j)} .
$$

We assume that price setting is constrained exogenously by a discrete time version of the mechanism suggested by Calvo (1983). Each firm has the opportunity to change its price with a given probability $1-\xi$. Moreover, we assume that when a firm has the opportunity to do so, it sets the new price in order to maximize the expected discounted value of net profits before the realization of shocks in a given period. ${ }^{7}$ Firms that do not reoptimize in a certain period index their price to last period's producer price inflation, where the degree of indexation is given by the parameter $\kappa \in[0,1]$.

In setting the new price $P_{t}^{A, P C P}(j)$, the problem of a generic PCP-firm is given by

$$
\max \sum_{k=0}^{\infty} \xi^{k} E_{t-1}\left(\frac{Q_{t, t+k} Y_{t+k}(j)}{P_{t+k}}\left[P_{t}^{A, P C P}(j) \prod_{s=1}^{k}\left(\Pi_{t+s-1}^{A}\right)^{\kappa}-M C_{t+k}\right]\right),
$$

subject to the demand function (9), the production function (15) and the optimality condition on factor inputs (16). ${ }^{8} \Pi_{t}^{A}=P_{t}^{A} / P_{t-1}^{A}$ denotes domestic inflation. Profits are discounted with the stochastic discount factor, $Q_{t, t+1}$, implicitly defined below.

The pricing problem of a generic LCP-firm is subject to the same constraints as those of the PCP-firm. It sets two distinct prices for the domestic and foreign market. The domestic price $P_{t}^{A, L C P}(j)$ is set to solve

$$
\max \sum_{k=0}^{\infty} \xi^{k} E_{t-1} \frac{Q_{t, t+k} A_{t+k}(j)}{P_{t+k}}\left[P_{t}^{A, L C P}(j) \prod_{s=1}^{k}\left(\Pi_{t+s-1}^{A}\right)^{\kappa}-M C_{t+k}\right],
$$

subject to the demand function (7), while $P_{t}^{A, L C P *}(j)$ is set to solve

$$
\max \sum_{k=0}^{\infty} \xi^{k} E_{t-1} \frac{Q_{t, t+k} A_{t+k}^{*}(j)}{P_{t+k}}\left[S_{t+k} P_{t}^{A, L C P *}(j) \prod_{s=1}^{k}\left(\Pi_{t+s-1}^{B}\right)^{\kappa}-M C_{t+k}\right]
$$

subject to the demand function (8).

\subsection{Households}

A representative household allocates consumption expenditures intertemporally on final goods and supplies labor, $H_{t}$, to intermediate good firms. The preferences of the household are given by

$$
\sum_{t=0}^{\infty} \beta^{t} \frac{\left[\left(C_{t}-b C_{t-1}\right)^{\mu}\left(1-H_{t}\right)^{1-\mu}\right]^{1-\gamma}}{1-\gamma}
$$

where $\beta$ is a time discount factor and $b \in[0,1)$ measures the extent of consumption habits. The parameters $\gamma$ and $\mu$ are positive constants characterizing preferences.

\footnotetext{
${ }^{7}$ In other words, period $t$ prices are set conditional on the information period $t-1$, see Christiano et al. (2005).

${ }^{8}$ In our formulation we implicitly assume that demand for intermediate good $j$ is met at all times.
} 
Households own the domestic capital stock, $K_{t}$, which is internationally immobile as are labor services. As in Christiano et al. (2005) it may be costly to adjust the level of investment, $I_{t}$. Specifically, the law of motion for capital is given by

$$
K_{t+1}=(1-\delta) K_{t}+\left[1-\Psi\left(I_{t} / I_{t-1}\right)\right] I_{t},
$$

where $\delta$ denotes the depreciation rate; restricting $\Psi(1)=\Psi^{\prime}(1)=0$ and $\Psi^{\prime \prime}(1)=\chi>0$ ensures that the steady state capital stock is independent of investment adjustment costs captured by $\chi$.

A complete set of state-contingent securities is traded at an international level. Letting $\Xi_{t+1}$ denote the period $t+1$ payoff of the portfolio held at the end of period $t$, the gross short-term nominal interest rate, $\left(1+i_{t}\right)$, is implicitly defined by $\left(1+i_{t}\right)^{-1}=E_{t} Q_{t, t+1}$, while the budget constraint reads as follow

$$
W_{t} H_{t}+R_{t} K_{t}+\Upsilon_{t}+T_{t}-P_{t}\left(C_{t}+X_{t}\right)=E_{t}\left\{Q_{t, t+1} \Xi_{t+1}\right\}-\Xi_{t} .
$$

$\Upsilon_{t}$ denotes nominal profits earned by monopolistic firms and transferred to households and $T_{t}$ denotes lump-sum taxes. We assume that government spending is financed entirely through lump-sum taxes: $T_{t}=P_{t} G_{t}$.

We assume that the household decides on consumption and investment expenditures in period $t$ before period- $t$ uncertainty is revealed. Subject to this additional constraint as well as to (21) and (22), the household maximizes the expected value of (20).

\subsection{Monetary Policy}

To close the model, we assume that monetary policy is characterized by an interest rate feedback rule as in Clarida, Galí, and Gertler (2000). Specifically, we assume for the interest rate

$$
i_{t}=\rho i_{t-1}+(1-\rho)\left(i+\beta^{-1} \phi_{\pi}\left(\Pi_{t}^{A}-\Pi^{A}\right)+(4 F \beta)^{-1} \phi_{y}\left(F_{t}-F\right)\right)+\nu_{t},
$$

where letters without time subscript refer to steady state values. The parameter $\rho \in[0,1]$ captures interest rate smoothing, $\phi_{\pi}$ captures the long-run adjustment of the interest rate to producer price inflation and $\phi_{y}$ captures stabilization of domestic absorption. ${ }^{9}$ Finally, $\nu_{t}$ represents a zero-mean shock to the short-term interest rate not accounted for by the systematic feedback rule. It thus represents a monetary policy shock.

\footnotetext{
${ }^{9} \mathrm{We}$ assume that monetary policy responds to domestic inflation and absorption, because under this assumption we can identify monetary policy shocks in our VAR model in a way which is consistent with our theoretical model. Note also that in open economy models focusing on domestic inflation rather than CPI-inflation is often preferable from a welfare point of view, see Galí and Monacelli (2005). In addition, our formulation of the interest rate rule (23) is meant to facilitate a comparison of the parameter values $\phi_{\pi}$ and $\phi_{y}$ to those obtained in the empirical literature on interest rate rules where inflation and interest rate are typically annualized.
} 


\subsection{Model solution}

We solve the model numerically by applying standard techniques. Specifically, we use (23) together with the linearized first order conditions and constraints of the firms' and household problem as well as their foreign counterparts to determine the equilibrium allocation near the deterministic and symmetric steady state. We use the approximate solution of the model to investigate the effects of monetary policy shocks on the economy. To simplify the analysis, we focus on country differences, i.e. the behavior of a domestic variable relative to its foreign counterpart. Before discussing our strategy to assign parameter values, we briefly turn to the implications of strategic price-setting complementarities for the exchange rate channel of monetary policy transmission.

\subsection{The exchange rate channel revisited}

Strategic complementarities in price-setting may alter monetary policy transmission in open economies by adding a new dimension to the exchange rate channel. Traditionally, two dimensions of the exchange rate channel have been distinguished (see, for instance, Svensson, 2000). First, under sticky prices, nominal exchange rate changes translate into real exchange rate changes that in turn induce an expenditure switching effect. As a result, exchange rate changes alter the demand for domestic goods and thus affect domestic producer prices. Note that in this case, the exchange rate impacts only indirectly_ via demand — on domestic inflation. Second, nominal exchange rate changes feed directly into the prices of imported goods and hence into CPI-inflation. Both effects, however depend on the extent of exchange rate pass-through. If import prices are insulated from exchange rate movements, the exchange rate channel is failing to operate along both dimensions.

Strategic price-setting complementarities add a new dimension to the exchange rate channel. In order to show this formally, we focus on the case where exchange rate pass-through is complete $(\alpha=0)$ and derive a variant of the New Keynesian Phillips curve as an approximation of the intermediate goods firms' price setting problem around a deterministic, zero inflation steady state:

$$
E_{t-1} \pi_{t}=\beta E_{t-1} \pi_{t+1}+\lambda(1-\Psi) E_{t-1} m c_{t}+\lambda \Psi(1-\omega) \frac{2 \omega \tilde{\sigma}}{\epsilon} E_{t-1} q_{t},
$$

where $\pi_{t}$ denotes percentage points of domestic inflation, $m c_{t}$ measures the percentage deviation of marginal costs from steady state and $q_{t}$ denotes percentage deviation of the relative price of imports expressed in domestic currency. The coefficient $\lambda=(1-\beta \xi)(1-\xi) \xi^{-1}$ is familiar from the New Keynesian baseline model and provides a measure for the pass-through of marginal costs onto inflation. The coefficient $\Psi$ depends on the extent of strategic complementarities in price-setting and other structural parameters of the model: $\Psi=-1 \eta \epsilon(\epsilon(1-\eta)-1)^{-1} \cdot{ }^{10}$

\footnotetext{
${ }^{10}$ Expression (24) abstracts from indexation. In appendix A we derive the New Keynesian Phillips curve considering the general case $\alpha \in[0,1]$. Guerrieri et al. (2008) provide a derivation under the assumption that $\alpha=1$.
} 
The relationship (24) governs the dynamics of domestic inflation. Note that if $\eta=0$, we have $\Psi=0$ and the term $q_{t}$ disappears from the Phillips curve. In fact, in this case the Phillips curve takes the form which is well-known from the closed-economy New Keynesian baseline model. Clarida et al. (2001) and Galí and Monacelli (2005) have stressed this isomorphism, i.e. the fact that the form of the Phillips curve for the open economy corresponds to that of the closed economy. This case is nested in our model.

Turning to the case where such complementarities are present $(\eta<0 \rightarrow \Psi>0)$, we observe that the relative price of imports directly matters for domestic inflation. Consider, for instance, a decrease in the domestic currency price of imports resulting from an exchange rate appreciation. In this case, given strategic price-setting complementarities, domestic producers will find it optimal to lower their prices, because the price charged by foreign competitors is reduced: domestic inflation falls. In addition to the coefficient $\Psi$, two more parameters govern the strength of this effect. First, the larger the trade price elasticity relative to the elasticity of substitution across domestically produced goods $(\tilde{\sigma} / \epsilon)$, the stronger the impact of import prices on domestic inflation. Second, the impact will also be stronger, the more open an economy. This follows from imports making up for a larger fraction of the final goods basket, measured by $1-\omega$.

As a consequence, monetary policy may directly impact domestic inflation via the exchange rate. A monetary contraction which appreciates the nominal exchange rate and lowers the price of imports reduces domestic inflation. This adds a new dimension to the exchange rate channel, which is not present in models without price-setting complementarities. Its importance, however, depends on the extent of exchange rate pass-through in addition to the parameters discussed above. If import prices are unresponsive to exchange rate changes, the exchange rate channel fails to operate. In order to gauge its importance, we need to quantify the extent of exchange rate pass-through along with other key parameters of the model.

\section{Estimation}

Our model is agnostic as regards the sources of business cycle fluctuations and only allows for monetary policy shocks. Accordingly, by bringing the model to the data, we isolate fluctuations in actual time series which can be attributed to monetary policy shocks. Specifically, we focus on the empirical impulse response functions obtained from a VAR estimated on U.S. time series relative to an aggregate of industrialized countries. We use these statistics to pin down the values of key parameters of the model. Such a limited information approach enables our DSGE model to provide an empirically plausible account of the monetary transmission mechanism. ${ }^{11}$

\footnotetext{
${ }^{11}$ A natural alternative is to estimate the model using full information techniques. This would require to take a stand of all possible sources of business cycle fluctuations, which we can avoid for the purpose of the present study.
} 


\subsection{Empirical impulse response functions}

We estimate the VAR on quarterly time series data for the period 1973-2006. We focus on relative variables, i.e. the difference of a variable in the U.S. and its counterpart for an aggregate of industrialized countries, which is meant to proxy for the rest of the world ('ROW' for short), see also Clarida and Gali (1994) and Rogers (1999). Specifically, we consider the log of relative consumption, the log of relative investment, the difference in domestic inflation rates (computed on the basis of the GDP deflator), the difference in short term interest rates, the difference in CPI-inflation rates as well as real net exports for the U.S., where real net exports are defined as the log difference in deflated exports and imports. ${ }^{12}$ Letting $Y_{t}$ denote the vector of endogenous variables, we estimate the structural VAR model

$$
A(L) Y_{t}=\varepsilon_{t},
$$

where $A(L)=\sum_{i=0}^{4} A_{i} L^{i}, L Y_{t}=Y_{t-1}$ and $E\left(\varepsilon_{t} \varepsilon_{t}^{\prime}\right)=I$.

In order to identify (relative) monetary policy shocks, we assume that $A_{0}$ is lower triangular, i.e. we impose the recursive identification scheme which is frequently employed to study the effects of monetary policy shocks, see Kim (2001) for an open economy context. We attach a structural interpretation only to the innovation in relative short-term interest rates. Hence, what matters for identification is how the other variables in $Y_{t}$ are ordered relative to this variable, see Christiano, Eichenbaum, and Evans (1999). We order relative consumption, relative investment as well as the differential of domestic inflation before and the differential of CPI-inflation and net exports after the short-term interest rate differential. The implied identification assumptions are consistent with our DSGE model: consumption, investment and domestic inflation are predetermined relative to monetary policy shocks, while consumer (i.e. final goods) prices and real net exports are free to adjust immediately. As in the theoretical model, we are allowing monetary policy to adjust the interest rate contemporaneously to changes in domestic inflation and domestic absorption. ${ }^{13}$

Figure 1 displays the impulse responses to a monetary policy shock, i.e. an increase by 100 basis points in the U.S. short rate relative to the aggregate of industrialized countries. The solid line shows the point estimate, while the shaded area measures 90 percent confidence bounds obtained from bootstrap sampling. The upper row shows the responses of consumption and investment in relative

\footnotetext{
${ }^{12}$ We treat CPI-inflation as the empirical counterpart of the DSGE model's inflation rate for final goods. A detailed description of the data is given in appendix B. We remove a constant linear trend from consumption and investment before computing relative variables.

${ }^{13}$ Alternative approaches to identify monetary policy shocks in open economy frameworks consider on monetary aggregates and non-recursive identification schemes, see Eichenbaum and Evans (1995), Cushman and Zha (1997) and Kim and Roubini (2000). More recently, Faust and Rogers (2003) and Scholl and Uhlig (2008) use sign restrictions to achieve identification. These studies have typically been concerned with the behavior of the exchange rate in the face of monetary policy shocks and on the importance of the latter to account for fluctuations in the former. In the present paper, we are not taking up these issues. Instead, we use the VAR responses as a key statistic to pin down parameter values of our DSGE model.
} 

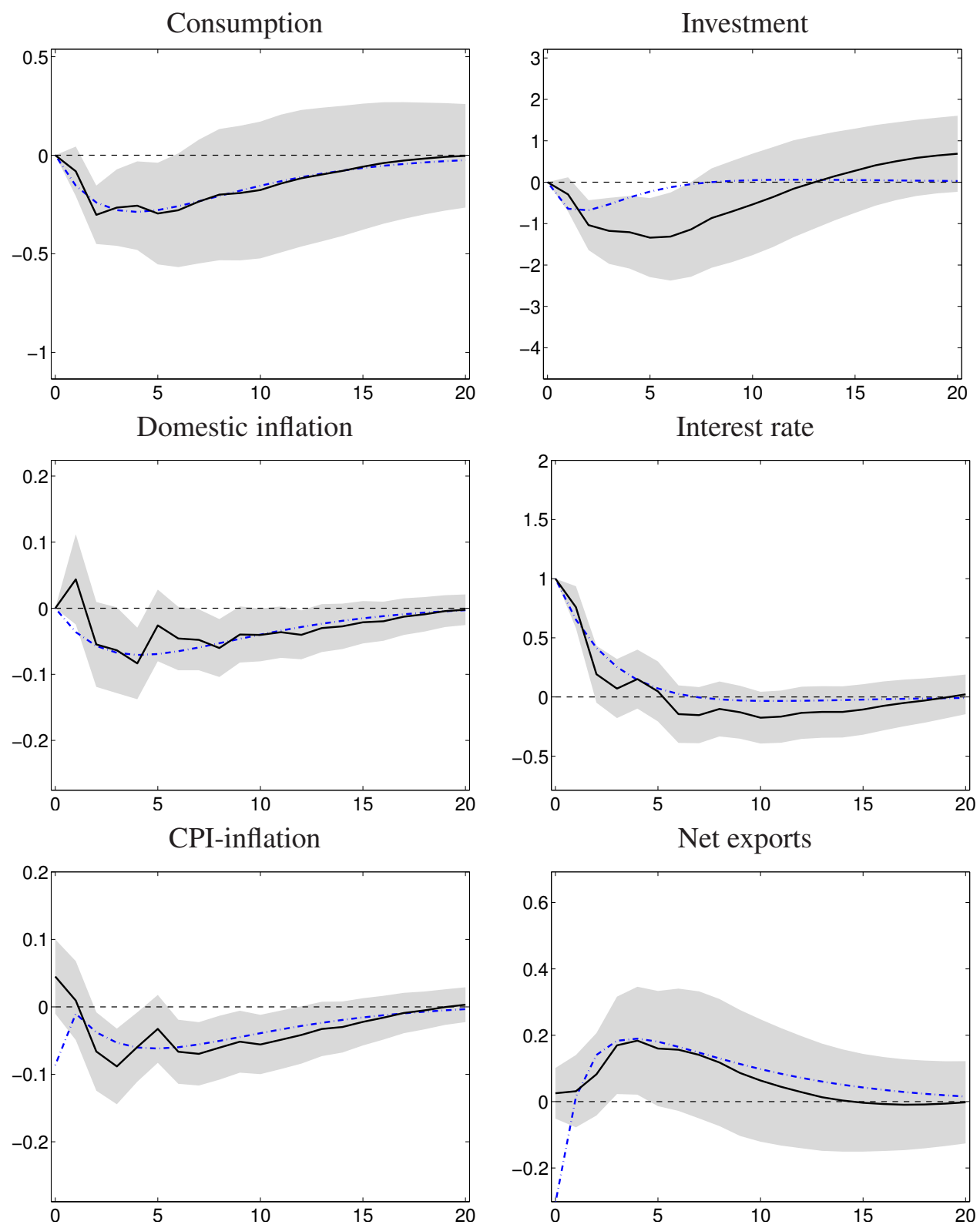

Figure 1: Effects of a monetary policy shock. Notes: Shock and responses are in relative terms (U.S. vs. ROW), except for net exports which is the log difference of U.S. exports and imports. Solid line: point estimate; shaded areas: bootstrapped 90 percent confidence intervals; dashed-dotted line: responses of estimated DSGE model; Vertical axes: percent, except for inflation and interest rate (percentage points). Horizontal axes: quarters. 
terms; for both we find a protracted and hump-shaped decline. While consumption falls by roughly 0.3 percent, investment falls by about 1.25 percent, with the maximum effect occurring between three and six quarters after the shock.

Domestic inflation responds somewhat sluggishly; the maximum decline of about 8 basis points is observed five quarters after the shock. According to our point estimate, it takes another 3 to 4 years for inflation to return to its pre-shock level. The shock to the interest rate differential is mildly persistent, with the short rate returning to its pre-shock level after about one year. The response of CPI-inflation is remarkably close to that of domestic inflation, both from a quantitative and a qualitative point of view. Finally, U.S. net exports display a hump-shaped increase with the maximum effect of about 0.2 percent occurring after about a year.

\subsection{Estimation of general equilibrium model}

The second step of the analysis consists in matching empirical and theoretical impulse responses in order to obtain estimates for the parameters of the DSGE model. This approach has gained popularity in closed economy studies of monetary policy transmission following the pioneering work of Rotemberg and Woodford (1997) and Christiano et al. (2005).

To illustrate this approach, define $I R^{e}$ to be the empirical impulse response function characterizing the data. The model itself assigns to each admissible vector of structural parameters $\theta$ a theoretical impulse response function $I R=I R(\theta)$. We obtain an estimate for the parameter vector of interest, $\widehat{\theta}$, by minimizing the weighted distance between empirical and theoretical impulse response functions, i.e., $I R^{e}$ and $I R$ :

$$
\widehat{\theta}=\arg \min \left(I R^{e}-I R(\theta)\right)^{\prime} W\left(I R^{e}-I R(\theta)\right),
$$

where $W$ represents a diagonal matrix whose diagonal entries are the reciprocal values of the variance of the empirical impulse responses. Using this weighting matrix ensures that the theoretical impulse responses are made to be as close to the empirical ones as possible, in terms of point-wise standard deviations. Regarding the length of the impulse response functions, we consider 20 quarters starting from the second quarter as most variables return to their steady state within 5 years.

The relationship between structural parameters and the implied impulse response functions is nonlinear; we therefore obtain theoretical impulse response functions by applying standard numerical techniques. Note that our procedure only admits saddle path stable solution and thus rules out by construction any parameterization of the model which would give rise to equilibrium indeterminacy.

Standard errors for $\widehat{\theta}$ are computed using the following expression for the asymptotic variance of our estimator, taken from Wooldridge (2002):

$$
\widehat{\operatorname{Avar}}(\widehat{\theta})=\left(G^{\prime} W G\right)^{-1}\left(G^{\prime} W \widehat{\Sigma} W G\right)\left(G^{\prime} W G\right)^{-1} .
$$


where $G=\nabla_{\theta} I R$ represents the Jacobian of the impulse response function generated from the model and $\widehat{\Sigma}$ denotes the variance matrix of the impulse responses obtained from bootstrap sampling.

\subsection{Parametric setup}

In practice, given the number of the structural parameters, it is not possible to identify all of them simultaneously. We therefore fix those parameters prior to the estimation which are either given by first moments of the data or are fairly uncontroversial.

First we set $\omega=0.88$ which implies an import-to-GDP ratio of 12 percent, the average value for the U.S. in our sample period. Moreover, we set, as, for instance, in Backus, Kehoe, and Kydland (1994) $\beta=0.99, \gamma=2$ and $\mu=0.34$ as well as $\theta=0.36$ and $\delta=0.025$. In addition, we assume that government spending accounts for 20 percent of GDP, close to the average in our sample period. Regarding price rigidities, we set $\xi=0.75$, which implies an average duration of prices of one year which is broadly in line with the evidence discussed in Nakamura and Steinsson (2008). We set $v$ such that the markup earned by intermediate goods firms in steady state is 20 percent.

We are thus left with nine parameters for which we seek to obtain estimates by solving (26). We estimate a value for the trade price elasticity, $\tilde{\sigma}$, by adjusting $\sigma$ according to the relationship (5). In addition, we pin down values for the parameters measuring investment adjustment costs, $\chi$, price indexation, $\kappa$, habits, $b$, as well as for those parameters which specify the interest rate feedback rule: $\phi_{\pi}, \phi_{y}$ and $\rho$. Two additional parameters, which are of particular importance for the international monetary transmission mechanism are $\alpha$, measuring the fraction of LCP-firms and $\eta$ which is directly related to the degree of strategic price-setting complementarities.

\subsection{Results}

Table 1 provides the estimation results. We find plausible point estimates and fairly narrow confidence bounds implied by the standard errors reported in parentheses. The estimated trade price elasticity is below the values often used or found in the literature. Yet several recent studies suggest that a low trade price elasticity may help to account for a larger set of macroeconometric observations, see Lubik and Schorfheide (2006), Kollmann (2006) and de Walque, Smets, and Wouters (2005). Also $\chi$, the parameter capturing investment adjustment costs is somewhat below the value reported in Christiano et al. (2005). This is likely to be the result of the aggregation function of final goods, see the discussion in Backus et al. (1994).

In line with earlier research we also find full indexation of prices, see, for instance, Meier and Müller (2006). Regarding monetary policy we find parameter values which imply a fairly loose monetary stance. Note, however, that our solution procedure rules out equilibrium indeterminacy. The degree of interest rate smoothing is in line with previous findings in the literature, see, for instance, Clarida 
Table 1: Estimated parameter values of DSGE model

\begin{tabular}{llc}
\hline Parameter & Description & \\
\hline$\tilde{\sigma}$ & Trade price elasticity & 0.48 \\
& Investment adjustment costs & $(0.63)$ \\
$\chi$ & Price indexation & $(0.69)$ \\
$\kappa$ & & 1.00 \\
& Inflation coefficient in policy rule & $(-)$ \\
$\phi_{\pi}$ & Output coefficient in policy rule & $(0.51)$ \\
$\phi_{y}$ & Interest rate smoothing & 0.01 \\
$\rho$ & Habits & $(0.13)$ \\
& & 0.67 \\
$b$ & Share of firms with local currency pricing & $0.09)$ \\
& & 0.90 \\
$\alpha$ & NCES-parameter & 0.88 \\
$\eta$ & & $(0.15)$ \\
& & -11.00 \\
\hline
\end{tabular}

Notes: Parameter estimates obtained from matching DSGE and VAR impulse response functions; standard errors are reported in parentheses. Those parameter values which have been estimated to be at their theoretical bounds have been assumed to take this value prior to estimation; in this case no standard error is reported.

et al. (2000) for the U.S. We find a considerable amount of habits in consumption, somewhat above the values reported in Smets and Wouters (2005) both for the euro area and the U.S.

For the share of firms engaged in LCP we find a value somewhere between 80 and 99 percent reported by Campa and Goldberg (2005) and Bergin (2006), respectively for the U.S. Finally, the estimate for the parameter $\eta$ provides a measure for the curvature of our demand functions. Our estimate is somewhat higher than the values assumed by Gust et al. (2006) and Guerrieri et al. (2008), but close to the value assumed by Smets and Wouters (2007) in a closed economy context.

In order to assess the implication of our estimate for $\eta$, we display in figure 2 the percentage change in demand for a generic good (vertical axis) resulting from a percentage change in its relative price (horizontal axis). The dashed line shows the implied demand function for our estimate of $\eta$, while the solid line displays the results for $\eta=0$ implying a constant elasticity of substitution (CES). Relative to the CES case, our estimate implies strongly curved demand functions. As a result, if the relative price increases, demand falls more than proportionally, while, if the relative price falls, demand increases less than proportionally. This induces strategic complementarities in price-setting, which, ceteris paribus, provides firms with an incentive to adjust prices so as to avoid large deviations from the domestic currency price charged by domestic and foreign competitors.

Given the estimated parameter values, we compute the impulse responses of the model and compare them to those obtained from the VAR model. The dashed-dotted lines in the panels of figure 1 show that the model responses track the empirical responses quite closely. All the responses are within 


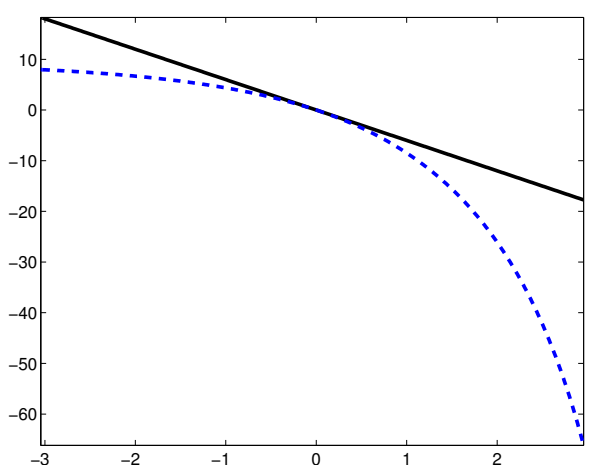

Figure 2: Demand function for intermediate goods. Notes: Solid line: CES case $(\eta=0)$; dashed-dotted line: NCES case $(\eta=-11.1)$; vertical axes: relative demand in percent; horizontal axes: relative price in percent.

the confidence bounds of the VAR responses, except for the impact response of CPI-inflation and net exports. Also the theoretical response of investment is somewhat less pronounced than its empirical counterpart. The response of the consumption differential, as well as those of domestic inflation and the interest rate are matched particularly closely. Overall, we conclude that the DSGE modelif evaluated at the point estimates-provides a quantitatively satisfactory account of the monetary transmission mechanism as apparent for the estimated VAR model.

\section{The role of openness in monetary policy transmission}

In this section we take up the question which motivates our investigation: does trade integration play a quantitatively important role for the transmission of monetary policy? Given that the estimated DSGE model provides a structural and quantitatively realistic account of the monetary transmission mechanism, it is well suited for counterfactual experiments which allow us to quantify the role of openness. We will also briefly explore some implications for monetary policy.

\subsection{The role of openness}

Several quantitative studies have demonstrated that it is possible to account for the actual transmission mechanism while abstracting from foreign trade altogether, see Christiano et al. (2005). At the same time, economies are bound to become more open as a result of increasing trade integration. While the average import share for the U.S. over the period 1973-2006 has been about 12 percent, it has been increasing secularly: from about 6 percent at the beginning of the sample to about 16 percent at the end of the sample. Interestingly, the trend seems to have been accelerating over the last 10 years or so. Against this background, we compare monetary transmission in the estimated model where imports account for 12 percent to two counterfactual scenarios: an approximately closed economy with imports accounting for less than 0.01 percent and a very open economy with imports accounting 
for 40 percent of final goods.

Figure 3 displays impulse responses of domestic inflation (upper row) and domestic absorption (lower row) to a domestic monetary policy shock, i.e. an exogenous increase in the nominal interest rate by 100 basis points. The responses in the left column are computed using the estimated DSGE model where all parameters, except for $\omega$, are kept at their (estimated) baseline values, notably $\alpha$ measuring the fraction LCP-firms. The dashed lines show the responses for the baseline case where imports account for 12 percent of GDP, while solid lines show the responses for the 'closed' economy; the dashed-dotted line shows the responses for the high-openness scenario. Recall that we focus on domestic inflation and absorption, because these variables are well defined in closed-economy models as well. ${ }^{14}$ A comparison of the responses reveals that openness matters very little for the transmission of monetary policy shocks in the estimated model (left column).

In a first step to interpret this results, recall that Clarida et al. (2001) and Galí and Monacelli (2005) have shown that there exists an isomorphic representation of the baseline New Keynesian model for closed and open economies. Specifically, the dynamic 'IS-curve' and the New Keynesian Phillips curve have the same structure. Relaxing the closed economy assumption induces only changes in the parameters governing the pass-through of marginal costs onto domestic inflation and the interest elasticity of demand, i.e. it alters only 'slope' coefficients. ${ }^{15}$ More specifically, Erceg et al. (2007) show that the difference between closed and open economies in this class of models can be attributed to the effects of a single composite parameter: the weighted average of the intertemporal elasticity of substitution and the trade price elasticity. As openness determines the relative weights, an increase in openness will alter the dynamic behavior of the economy strongly only if the trade price elasticity differs considerably from the intertemporal elasticity of substitution.

This result is useful in interpreting our finding. Abstracting from habit formation, our choice of parameter values for $\mu$ and $\gamma$ implies a value for the intertemporal elasticity of substitution for consumption of about $3 / 4$ which is in the middle of the range of the values discussed in the literature. Our estimate for the trade price elasticity suggests a value which is only slightly lower. It thus appears that because the trade price elasticity and the intertemporal elasticity of substitution are of similar magnitude, openness plays a very limited role in the monetary transmission mechanism. ${ }^{16}$

However, we have so far drawn on a discussion of the New Keynesian baseline model where strategic price-setting complementarities are absent, while we stressed a new dimension of the exchange rate channel emerging under such complementarities, see section 2.6. Specifically, in this case openness is

\footnotetext{
${ }^{14}$ The behavior of CPI inflation and output displays dynamics similar to domestic inflation and absorption, respectively. An exception is the impact period where changes in the nominal exchange rate and net exports dominate the behavior of domestic variables, because the latter are predetermined.

${ }^{15}$ Actually, for certain parameterizations even the difference in the slope coefficients disappears such that 'openness' is merely a source of additional shocks.

${ }^{16}$ In fact, when we increase the trade price elasticity, we find openness to impact more strongly on monetary transmission.
} 

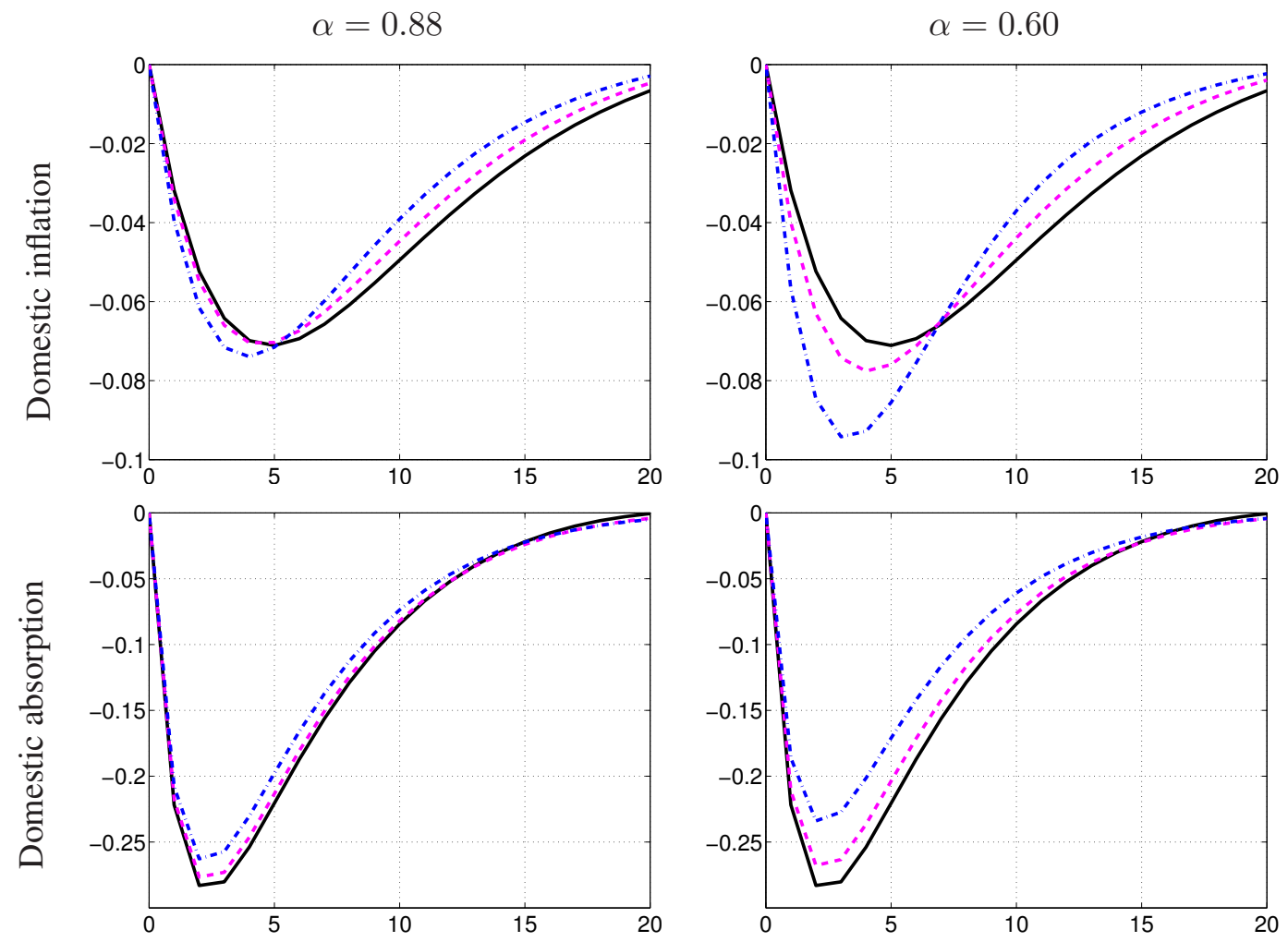

Figure 3: Impulse responses to monetary policy shock Notes: Shock is exogenous increase in domestic nominal interest rate by 100 basis points; lines show response of domestic variables. Solid line displays responses for zero import share; dashed line: 12 percent import share; dashed-dotted line: 40 percent; all parameter values are kept at the values used or obtained in the estimation of the model. 
likely to alter monetary transmission mechanism as it provides monetary policy with direct leverage on domestic inflation. Yet this effect is not evident in the response of domestic inflation displayed in figure 3-despite our estimate for $\eta$ which suggests strong complementarities.

Yet openness and complementarities are not sufficient for this effect to be present. As stressed above, a third condition is a fair amount of exchange rate pass-through. To see this, consider a monetary contraction: only if the resulting appreciation is reflected in foreign competitors charging lower domestic currency prices, will domestic firms find it optimal to lower their prices as well. In this case, there will be downward pressure on domestic inflation due to strategic complementarities, in addition to downward pressure resulting from muted demand and marginal costs.

In principle, this dimension of the exchange rate channel can be quite powerful from a quantitative point of view. This is illustrated in the upper right panel of figure 3, which displays the impulse responses of domestic inflation for the different degrees of openness, assuming a higher degree of exchange rate pass-through: we lower the value of $\alpha$ from our estimate of 0.88 to 0.6. In this case, increasing openness induces a much quicker and stronger fall in domestic inflation. In the open economy (40 percent imports, dashed-dotted line) the response peaks after 3 quarters rather than after 5 quarters in the closed economy. Moreover, the strength of the response increases by some 25 percent. ${ }^{17}$

The lower panels of figure 3 display the response of domestic absorption for all three openness scenarios, both for $\alpha=0.88$ (left panel) and $\alpha=0.6$ (right panel). Generally, domestic absorption falls less in response to the monetary policy shock in the more open economy. The effect of openness, however, is considerably more pronounced if the fraction of LCP-firms is lower, i.e. if exchange rate pass-through is higher. To understand this result, recall that while a monetary policy shock is an exogenous increase in the nominal interest rate, what matters for the dynamic adjustment of domestic absorption is the ex ante real interest rate. Its response depends on the dynamics of CPIinflation which, in turn, will vary with the degree of openness. On impact, CPI-inflation falls more strongly than domestic inflation, because of the exchange rate appreciation. Yet as the exchange rate overshoots, subsequent changes in the exchange rate tend to raise CPI-inflation relative to domestic inflation - thereby dampening the rise in the real rate. Hence, the fall in domestic absorption is less pronounced in more open economies. Again, this effect is stronger, the more pervasive exchange rate pass-through.

\footnotetext{
${ }^{17}$ Interestingly, Erceg et al. (2007) also discuss results for the NCES case. However, they still find that the role of openness (for the transmission of technology shocks) is limited which is likely to be the result of assuming that all firms engage in LCP.
} 
Import-GDP ratio

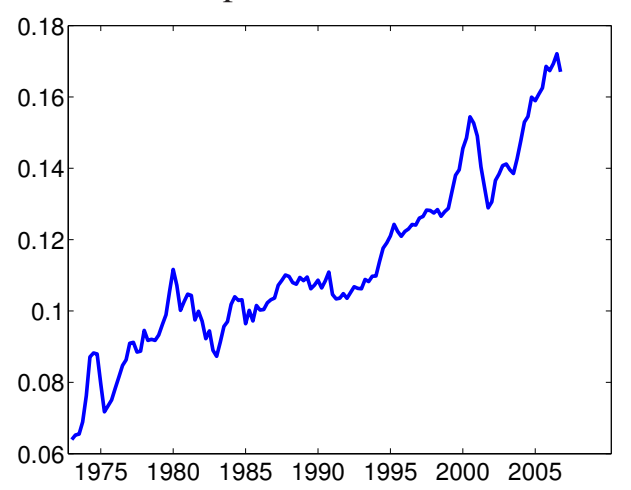

Exchange rate pass-through

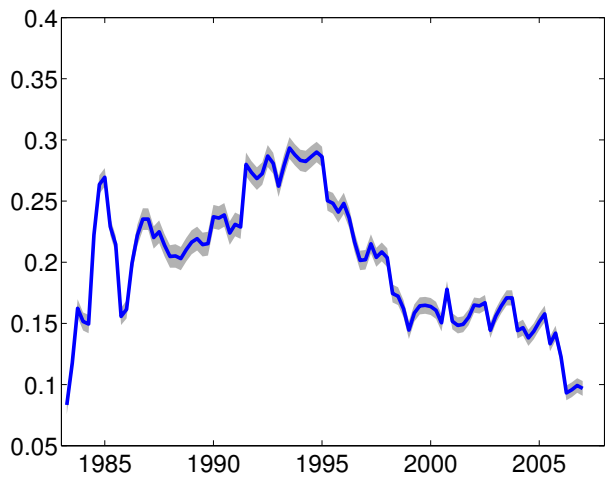

Figure 4: Openness and pass-through for the U.S. Notes: Left panel displays import-GDP ratio; right panel displays reduced form estimate of exchange rate pass-through for 10 year rolling window recursive estimates, shaded area displays two-standard error confidence bounds.

\subsection{Implications for monetary policy}

Assuming strategic complementarities in price setting, monetary policy gains better control over domestic inflation as trade integration increases, at least in principle. A necessary condition is that import prices are not completely isolated from exchange rate movements. Yet our estimates suggest that exchange rate pass-through is fairly limited. Moreover, several recent studies suggest that exchange rate pass-through has been declining over the last one or two decades. Figure 4 provides suggestive evidence for recent trends both in trade integration and exchange rate pass-through in the U.S. The left panel displays the import-to-GDP ratio over the period 1973-2006. The right panel displays a reduced-form recursive estimate of exchange rate pass-through for the same period. ${ }^{18}$ Our results, suggesting a decline in pass-through over the last 10-15 years, are broadly in line with those obtained in the literature, see, for instance, Marazzi et al. (2005) and Ihrig, Marazzi, and Rothenberg (2006).

Hence, it appears that although openness is on the rise, pass-through will continue to decline, if current trends prevail. This observation has important implications for monetary policy. To assess this more formally, we compute, as a measure for the trade-off faced by monetary policy, the cumulative reduction in domestic absorption relative to the cumulative reduction in domestic inflation for the first year after a monetary policy shock. ${ }^{19}$ Again we consider counterfactual scenarios and compare

\footnotetext{
${ }^{18} \mathrm{As}$ it is not possible to obtain rolling window estimates based on the structural estimation approach employed above, we resort to reduced form estimates. Specifically, similar to Gust et al. (2006) we regress recursively, using a 10 year rolling window, the log-differenced relative import price (measured as the nominal price of non-commodity imports of goods and services divided by the CPI-Index) on the log-differenced real effective exchange rate and a constant.

${ }^{19}$ To be precise about the trade-off faced by monetary policy, it would be necessary to specify an objective for monetary policy. Assuming that monetary policy aims at stabilizing both domestic inflation and the output gap, one may argue that there is no real trade-off in the present model: if both monetary authorities stabilize domestic inflation perfectly, they are likely to stabilize the output gaps as well. However, this is only true in the absence of cost-push shocks, which are typically found to be an important source of business cycle fluctuations, see Smets and Wouters (2007). While our model is agnostic
} 
Table 2: Monetary policy trade-off

\begin{tabular}{lll}
\hline $1-\omega$ & $\alpha$ & \\
\hline 0.00 & 0.88 & 4.8 \\
0.12 & 0.88 & 4.5 \\
0.40 & 0.88 & 3.9 \\
0.40 & 0.60 & 2.6 \\
\hline
\end{tabular}

Notes: Right column measures cumulative reduction in domestic absorption relative to domestic inflation for the first year after monetary policy shock.

it to our baseline case: an economy which is approximately closed and an economy where imports account for 40 percent. First, we keep pass-through low (at the value implied by our estimate of $\alpha=0.88$ ), but allow, in a last experiment, for higher pass-through by lowering $\alpha$ to 0.6.

Table 2 reports the results, which confirm our earlier findings. As a result of strategic price-setting complementarities, monetary policy has direct leverage on domestic inflation, which operates irrespectively of a contraction in demand. The more open the economy, the stronger this effect appears. At the same time, domestic absorption falls by less, because the monetary contraction implies a smaller increase in the real interest rate. Both effects tend to improve our trade-off measure. Yet from a quantitative point of view, this improvement is contained if pass-through is limited-as becomes apparent from the results of the fourth experiment (last row) where pass-through is increased to counterfactually high levels.

It thus appears that, as long as exchange rate pass-through remains limited, increasing trade openness has little bearing on the monetary transmission mechanism and the trade-off faced by monetary policy. ${ }^{20}$ As a matter of fact, current trends suggest that while trade integration is increasing, passthrough is decreasing. Yet it is conceivable that both phenomena are intertwined at a fundamental level. While the present framework has allowed us to study isolated the effects of features, it seems worthwhile to explore the possibility of a joint cause for both trends in future research. ${ }^{21}$

about the sources of business cycle fluctuations, our measure for the monetary policy trade-off might provide some idea of how much reduction in domestic demand is necessary in order to engineer a certain reduction in domestic inflation. Our measure is thus related to the sacrifice ratio, except that we do not consider a permanent reduction in inflation.

${ }^{20}$ Erceg et al. (2007) simulate the reduction of the inflation target incorporated in an interest rate feedback rule using the SIGMA model of the FED. They compute the sacrifice ratio for different degrees of openness finding no important role for the latter. Note, however, that while they assume strategic complementarities in price-stetting, they also assume LCP such that import prices are isolated from exchange rate changes in the short-run.

${ }^{21}$ Dornbusch (1987) argues that the extent of exchange rate pass-through and goods market integration are jointly determined. Gust et al. (2006) also link trade integration and exchange rate pass-through in a framework with strategic complementarities. However, they abstract from nominal rigidities. 


\section{Conclusion}

In this paper we explore the role of trade integration for monetary policy transmission. First, we develop a New Keynesian DSGE model featuring two symmetric countries and several frictions which recent business cycle research has found to be important in accounting for several macroeconometric observations. In addition, following Gust et al. (2006), Sbordone (2007) and Guerrieri et al. (2008), we assume a fairly general aggregation technology for final goods. It induces strategic complementarities in price-setting with respect to domestic and foreign competitors such that domestic firms will find it optimal to adjust their prices in response to exchange rate changes which alter the domestic currency price of imports - a new dimension of the exchange rate channel by which monetary policy gains direct leverage over domestic inflation.

In order to quantify the effects of openness on monetary transmission, we estimate, in a first step, a VAR on U.S. time series relative to an aggregate of industrialized countries. We identify monetary policy shocks by imposing an identification scheme which is consistent with our theoretical model and trace out the transmission mechanism through impulse response functions. In a second step, we find parameter values of the DSGE model by matching its impulse responses to those obtained from the VAR. We find that the estimated model is generally able to mimic the empirical response functions quite closely. Importantly, for the model to do so, we require a low value for the trade price elasticity and the exchange rate pass-through, but strong complementarities in price-setting.

In a third step, we compare the effects of a monetary policy shock in the estimated model where imports account for 12 percent of final goods to two alternative scenarios: an economy which is approximately closed and one in which imports account for 40 percent. We find the effects on domestic inflation and absorption to be almost identical. Closer inspection reveals two reasons underlying this finding. First, the estimated value of the trade price elasticity is close to the intertemporal elasticity of substitution. In this case, openness has been shown to induce little change in the New Keynesian baseline model, see Erceg et al. (2007). Second, as regards the new dimension of the exchange rate channel, we find that limited exchange rate pass-through prevents it from having strong quantitative effects. If we repeat our experiment while assuming higher exchange rate pass-through, the effects of monetary policy shocks become considerably stronger.

Finally, turning to the implications for monetary policy, we stress that while increasing openness could, in principle, improve the trade-off faced by monetary policy, such a development is likely to be prevented by low exchange rate pass-through. At current trends, it appears that while trade integration, or openness, is on the rise, exchange rate pass-through is declining as far as major industrialized countries are concerned. We conclude that while policy makers should keep a close eye on the joint development of openness and exchange rate pass-through, future research may investigate possible causes underlying these trends. 


\section{A The New Keynesian Phillips curve}

In the following, we go through the main steps of deriving the New Keynesian Phillips curve equation (24). We split the derivation into 3 parts. In part one we solve the pricing problem of a generic intermediate good LCP-firm in the domestic market (eq. 18). Part 2 solves the pricing problem of a generic intermediate good PCP-firm in the domestic market (eq. 17). In part 3 we bring the first parts together using the first order approximation of the definition of the producer price index.

\section{A.1 Pricing problem of LCP-firm}

Defining $I_{t+k}=\prod_{s=1}^{k}\left(\Pi_{t+s-1}^{A}\right)^{\kappa}$ and maximizing equation (18) subject to the demand function (7), we derive the following first order condition

$$
E_{t-1} \sum_{k=0}^{\infty} \xi^{k} Q_{t, t+k}\left(P_{t+k}\right)^{-1} I_{t+k}\left[1-\left(1-\frac{M C_{t+k}}{I_{t+k} P_{t}^{A, L C P}(j)}\right) \epsilon_{t+k}(j)\right] A_{t+k}(j)=0
$$

where the elasticity of demand for good $j$ in the domestic market is

$$
\epsilon_{t+k}(j)=\frac{1}{1-v}\left[1+\eta\left(\frac{P_{t}^{A, L C P}(j) I_{t+k}}{P_{t+k}^{A}}\right)^{\frac{1}{1-v}}\left(\frac{P_{t+k}^{A}}{\Gamma_{t+k}}\right)^{\frac{-\sigma}{\sigma(v-1)-v}}\right]^{-1} .
$$

Rewriting equation (28) using the definition of real marginal cost $M C_{t}^{R}=\frac{M C_{t}}{P_{t}^{A}}$, defining the contract price as $P_{t}^{A Q, L C P}(j)=\frac{P_{t}^{A, L C P}(j)}{P_{t}^{A}}$ and linearizing gives

$$
\begin{aligned}
& E_{t-1}\left[\widehat{P}_{t}^{A Q, L C P}(j)\right]=\sum_{k=1}^{\infty}(\beta \xi)^{k} E_{t-1}\left[\widehat{\Pi}_{t+s}^{A}-\kappa \widehat{\Pi}_{t+s-1}^{A}\right] \\
& +(1-\beta \xi) \sum_{k=0}^{\infty}(\beta \xi)^{k} E_{t-1}\left[\widehat{M C}_{t+k}^{R}-\frac{1}{\epsilon-1} \widehat{\epsilon}_{t+k}(j)\right] .
\end{aligned}
$$

In the above equation all variables are expressed in log-deviations from steady-state. Log-linearizing the elasticity of demand for good $j$ equation (29), with $\Gamma_{t}^{Q}=\frac{\Gamma_{t}}{P_{t}^{A}}$, we get

$$
\widehat{\epsilon}_{t+k}(j)=-\eta \epsilon\left(\widehat{P}_{t}^{A Q, L C P}(j)-\sum_{k=1}^{\infty}\left(\widehat{\Pi}_{t+s}^{A}-\kappa \widehat{\Pi}_{t+s-1}^{A}\right)\right)+\eta \tilde{\sigma} \widehat{\Gamma}_{t+k}^{Q} .
$$

Substituting this expression for the demand elasticity in the first order condition, we have

$$
\begin{aligned}
& E_{t-1}\left[\widehat{P}_{t}^{A Q, L C P}(j)\right]=\sum_{k=1}^{\infty}(\beta \xi)^{k} E_{t-1}\left[\widehat{\Pi}_{t+s}^{A}-\kappa \widehat{\Pi}_{t+s-1}^{A}\right] \\
& +\left(\frac{1-\beta \xi}{1-\frac{\eta \epsilon}{\epsilon-1}}\right) \sum_{k=0}^{\infty}(\beta \xi)^{k} E_{t-1}\left[\widehat{M C}_{t+k}^{R}-\frac{\eta \epsilon}{\epsilon-1} \frac{\tilde{\sigma}}{\epsilon} \widehat{\Gamma}_{t+k}^{Q}\right] .
\end{aligned}
$$


Using the definition of the steady state markup $\mu=\frac{\epsilon}{\epsilon-1}$ and the definition of $\Psi=\frac{-\eta \mu}{1-\eta \mu}$, this expression after quasi-differencing can be written as

$$
\begin{aligned}
& E_{t-1}\left[\widehat{P}_{t}^{A Q, L C P}(j)-\beta \xi \widehat{P}_{t+1}^{A Q, L C P}(j)\right]=\beta \xi E_{t-1}\left(\widehat{\Pi}_{t+1}^{A}-\kappa \widehat{\Pi}_{t}^{A}\right) \\
& +(1-\beta \xi) E_{t-1}\left[(1-\Psi) \widehat{M C} \widehat{C}_{t}^{R}+\Psi \frac{\tilde{\sigma}}{\epsilon} \widehat{\Gamma}_{t}^{Q}\right] .
\end{aligned}
$$

The log-linearized version of the competitive price index equation (13) in the domestic country implies that

$$
\widehat{\Gamma}_{t}^{Q}=(1-\omega) \widehat{q}_{t},
$$

where $q_{t}=\frac{P_{t}^{B}}{P_{t}^{A}}$ is the relative import price in domestic currency. Using this to substitute for the relative competitive price index above we get

$$
\begin{aligned}
& E_{t-1}\left[\widehat{P}_{t}^{A Q, L C P}(j)-\beta \xi \widehat{P}_{t+1}^{A Q, L C P}(j)\right]=\beta \xi E_{t-1}\left(\widehat{\Pi}_{t+1}^{A}-\kappa \widehat{\Pi}_{t}^{A}\right) \\
& +(1-\beta \xi) E_{t-1}\left[(1-\Psi) \widehat{M C}_{t}^{R}+\Psi \frac{\tilde{\sigma}}{\epsilon}(1-\omega) \widehat{q}_{t}\right] .
\end{aligned}
$$

\section{A.2 Pricing problem of PCP-firm}

We can derive a similar expression for the PCP-firms. Maximizing equation (17) subject to the demand function (9), we derive the following first order condition:

$E_{t-1} \sum_{k=0}^{\infty} \xi^{k} Q_{t, t+k}\left(P_{t+k}\right)^{-1} I_{t+k}\left[Y_{t+k}-\left(1-\frac{M C_{t+k}}{I_{t+k} P_{t}^{A, P C P}(j)}\right)\left(\epsilon_{t+k}^{H}(j) A_{t+k}(j)+\epsilon_{t+k}^{F}(j) A_{t+k}^{*}(j)\right)\right]=0$,

where the elasticity of demand for good $j$ in the domestic market is similar to the LCP-firms problem

$$
\epsilon_{t+k}^{H}(j)=\frac{1}{1-v}\left[1+\eta\left(\frac{P_{t}^{A, P C P}(j) I_{t+k}}{P_{t+k}^{A}}\right)^{\frac{1}{1-v}}\left(\frac{P_{t+k}^{A}}{\Gamma_{t+k}}\right)^{\frac{-\sigma}{\sigma(v-1)-v}}\right]^{-1},
$$

and the elasticity of demand for good $j$ in the foreign market is given by

$$
\epsilon_{t+k}^{F}(j)=\frac{1}{1-v}\left[1+\eta\left(\frac{P_{t}^{A, P C P}(j) I_{t+k}}{S_{t+k} P_{t+k}^{A *}}\right)^{\frac{1}{1-v}}\left(\frac{P_{t+k}^{A *}}{\Gamma_{t+k}^{*}}\right)^{\frac{-\sigma}{\sigma(v-1)-v}}\right]^{-1} .
$$

Linearizing the first order condition of the firms problem using $P_{t}^{A Q, P C P}(j)=\frac{P_{t}^{A, P C P}(j)}{P_{t}^{A}}$ gives

$$
\begin{aligned}
& E_{t-1}\left[\widehat{P}_{t}^{A Q, P C P}(j)\right]=\sum_{k=1}^{\infty}(\beta \xi)^{k} E_{t-1}\left[\widehat{\Pi}_{t+s}^{A}-\kappa \widehat{\Pi}_{t+s-1}^{A}\right] \\
& +(1-\beta \xi) \sum_{k=0}^{\infty}(\beta \xi)^{k} E_{t-1}\left[\widehat{M C}_{t+k}^{R}-\frac{1}{\epsilon-1} \omega \widehat{\epsilon}_{t+k}^{H}(j)-\frac{1}{\epsilon-1}(1-\omega) \widehat{\epsilon}_{t+k}^{F}(j)\right] .
\end{aligned}
$$


Linearizing both demand elasticities defining $\Gamma_{t}^{Q *}=\frac{\Gamma_{t}^{*}}{P_{t}^{A *}}$ and the law-of-one-price gap as $q_{t}^{A *}=$ $\frac{S_{t} P_{t}^{A *}}{P_{t}^{A}}$ gives

$$
\begin{aligned}
& \widehat{\epsilon}_{t+k}^{H}(j)=-\eta \epsilon\left(\widehat{P}_{t}^{A Q, P C P}(j)-\sum_{k=1}^{\infty}\left(\widehat{\Pi}_{t+s}^{A}-\kappa \widehat{\Pi}_{t+s-1}^{A}\right)\right)+\eta \tilde{\sigma} \widehat{\Gamma}_{t+k}^{Q}, \\
& \widehat{\epsilon}_{t+k}^{F}(j)=-\eta \epsilon\left(\widehat{P}_{t}^{A Q, P C P}(j)-\sum_{k=1}^{\infty}\left(\widehat{\Pi}_{t+s}^{A}-\kappa \widehat{\Pi}_{t+s-1}^{A}\right)-\widehat{q}_{t+k}^{A *}\right)+\eta \tilde{\sigma} \widehat{\Gamma}_{t+k}^{Q *} .
\end{aligned}
$$

Substituting the demand elasticities into the first order condition and simplifying yields

$$
\begin{aligned}
& E_{t-1}\left[\widehat{P}_{t}^{A Q, P C P}(j)\right]=\sum_{k=1}^{\infty}(\beta \xi)^{k} E_{t-1}\left[\widehat{\Pi}_{t+s}^{A}-\kappa \widehat{\Pi}_{t+s-1}^{A}\right] \\
& +(1-\beta \xi) \sum_{k=0}^{\infty}(\beta \xi)^{k} E_{t-1}\left[(1-\Psi) \widehat{M C}_{t+k}^{R}+\Psi \omega \frac{\tilde{\sigma}}{\epsilon} \widehat{\Gamma}_{t+k}^{Q}+\Psi(1-\omega) \frac{\tilde{\sigma}}{\epsilon} \widehat{\Gamma}_{t+k}^{Q *}+\Psi(1-\omega) \widehat{q}_{t+k}^{A *}\right] .
\end{aligned}
$$

After quasi-differencing, the expression can be rewritten as

$$
\begin{aligned}
& E_{t-1}\left[\widehat{P}_{t}^{A Q, P C P}(j)-\beta \xi \widehat{P}_{t+1}^{A Q, P C P}(j)\right]=\beta \xi E_{t-1}\left(\widehat{\Pi}_{t+1}^{A}-\kappa \widehat{\Pi}_{t}^{A}\right) \\
& +(1-\beta \xi) E_{t-1}\left[(1-\Psi) \widehat{M C}_{t}^{R}+\Psi \omega \frac{\tilde{\sigma}}{\epsilon} \widehat{\Gamma}_{t}^{Q}+\Psi(1-\omega) \frac{\tilde{\sigma}}{\epsilon} \widehat{\Gamma}_{t}^{Q *}+\Psi(1-\omega) \widehat{q}_{t}^{A *}\right] .
\end{aligned}
$$

One can linearize the competitive price index in the foreign country analogously to the one in the home country defining the relative export price in foreign currency as $q_{t}^{B *}=\frac{P_{t}^{A *}}{P_{t}^{B *}}$ :

$$
\widehat{\Gamma}_{t}^{Q *}=-\omega \widehat{q}_{t}^{B *}
$$

Using this expression and equation (31) to substitute for the relative competitive price indices above we get

$$
\begin{aligned}
& E_{t-1}\left[\widehat{P}_{t}^{A Q, P C P}(j)-\beta \xi \widehat{P}_{t+1}^{A Q, P C P}(j)\right]=\beta \xi E_{t-1}\left(\widehat{\Pi}_{t+1}^{A}-\kappa \widehat{\Pi}_{t}^{A}\right) \\
& +(1-\beta \xi) E_{t-1}\left[(1-\Psi) \widehat{M C}_{t}^{R}+\Psi(1-\omega) \omega \frac{\tilde{\sigma}}{\epsilon} \widehat{q}_{t}^{B}-\Psi(1-\omega) \omega \frac{\tilde{\sigma}}{\epsilon} \widehat{q}_{t}^{B *}+\Psi(1-\omega) \widehat{q}_{t}^{A *}\right] .
\end{aligned}
$$

\section{A.3 New Keynesian Phillips Curve}

The log-linearized version of the producer price index, equation (10), reads as

$$
\alpha \widehat{P}_{t}^{A Q, L C P}(j)+(1-\alpha) \widehat{P}_{t}^{A Q, P C P}(j)=\frac{\xi}{1-\xi}\left(\widehat{\Pi}_{t}^{A}-\kappa \widehat{\Pi}_{t-1}^{A}\right) .
$$

Using the final equations in the two subsections above to substitute for the contract prices of LCPand PCP-firms one finally obtains a general formulation for the New Keynesian Phillips curve:

$$
\begin{aligned}
& E_{t-1}\left(\widehat{\Pi}_{t}^{A}-\kappa \widehat{\Pi}_{t-1}^{A}\right)=\beta E_{t-1}\left(\widehat{\Pi}_{t+1}^{A}-\kappa \widehat{\Pi}_{t}^{A}\right) \\
& +\lambda E_{t-1}\left[(1-\Psi) \widehat{M C}_{t}^{R}+\Psi\left((1-\omega)(\alpha+(1-\alpha) \omega) \frac{\tilde{\sigma}}{\epsilon} \widehat{q}_{t}^{B}-(1-\omega) \omega(1-\alpha) \frac{\tilde{\sigma}}{\epsilon} \widehat{q}_{t}^{B *}+(1-\omega)(1-\alpha) \widehat{q}_{t}^{A *}\right)\right]
\end{aligned}
$$


with $\lambda=(1-\beta \xi)(1-\xi) \xi^{-1}$.

The special cases with $\alpha=0$ and $\eta=0$ are discussed in section 2.6. Here we briefly discuss the case of incomplete pass-through $(0<\alpha<1)$ and strategic complementarities in price setting $(\eta<0)$. In addition to the closed economy Phillips curve or the open economy Phillips curve without strategic complementarities three additional terms show up: $\widehat{q}_{t}^{B}, \widehat{q}_{t}^{B *}$ and $\widehat{q}_{t}^{A *}$. We discuss the underlying economics in turn focusing on a monetary contraction which appreciates the nominal exchange rate. A reduction of the relative import price $\widehat{q}_{t}^{B}$, induces domestic LCP firms to reduce their prices as their demand elasticity increases with a decrease of the import price index relative to the domestic price index. Domestic PCP-firms react in a similar way; in addition they adjust their price to changes in the relative export prices.

Following a nominal appreciation, the relative export price of PCP-firms expressed in foreign currency, $\widehat{q}_{t}^{B *}$, increases. Recall that PCP-firms can adjust export prices only through adjustments in domestic prices which are then translated via the law of one price into foreign currency. Hence, the increase in the export price, puts downward pressure on (domestic currency) price of PCP-firms.

Following a nominal appreciation, the export prices PCP-firms increase relative to the export prices of LCP-firms - in foreign currency terms. This is captured by a decrease in $\widehat{q}_{t}^{A *}$. As the PCP-firms can adjust their export price only by adjusting their domestic price, this puts additional downward pressure on domestic prices of PCP-firms.

All these effects become stronger with the degree of strategic price-setting complementarities $\eta$ and the import share $1-\omega$. As stressed in the main text, the effects also depend on the degree of exchange rate pass-through. Note that if there are only LCP-firms $(\alpha=1)$, the last two terms in the New Keynesian Phillips Curve drop out and only real marginal cost and the relative import price govern the domestic inflation dynamics. Yet, in this case import prices do not directly respond to exchange rate changes. 


\section{B Data}

Our data are obtained from the OECD Economic Outlook database, see OECD (2007). The ROW aggregate comprises data for Canada, the U.K., Japan and the Euro area. We use data for private consumption (volume), private fixed investment (excl. stockbuilding, volume), and the deflator for private consumption and the deflator for GDP. The latter series are used to construct the CPI-inflation and domestic inflation, respectively.

To construct a measure for net exports of the U.S., we deflate exports (exports of goods and services, value, local currency) and imports (imports of goods and services, value, local currency) with their deflators (export or import price goods and services, local currency) and compute the log-difference of both series. Measures for the short term interest rates are also obtained from the Economic Outlook database (interest rate, short-term) except for the Euro area. In this case we draw on data (STN) from the Area-Wide Model database of the ECB, see Fagan, Henry, and Mestre (2001).

To compute the ROW series, we calculate quarterly growth rates and aggregate these series on the basis of GDP weights (PPP-adjusted, year 2000), based on data from the IMF (2007). To obtain levels, we cumulate aggregated growth rates. 


\section{References}

M. Adolfson, S. Laséen, J. Lindé, and M. Villani. Bayesian estimation of an open economy DSGE model with incomplete pass-through. Journal of International Economics, 72(2):481-511, 2007.

J. D. Amato and T. Laubach. Estimation and control of an optimization-based model with sticky prices and wages. Journal of Economic Dynamics and Control, 27(7):1181-1215, 2003.

D. Backus, P. Kehoe, and F. Kydland. Dynamics of the trade balance and the terms of trade: the J-curve? American Economic Review, 84(1):84-103, March 1994.

P. R. Bergin. How well can the new open economy macroeconomics explain the exchange rate and current account? Journal of International Money and Finance, 25(5):675-701, 2006.

B. S. Bernanke. Globalization and monetary policy. Speech at the Fourth Economic Summit, Stanford Institute for Economic Policy Research, 2007.

C. Betts and M. B. Devereux. The exchange rate in a model of pricing-to-market. European Economic Review, 40(3-5):1007-1021, 1996.

C. Betts and M. B. Devereux. Exchange rate dynamics in a model of pricing-to-market. Journal of International Economics, 50(1):215-244, 2000.

J. Bovin and M. Giannoni. Has monetary policy become more effective? The Review of Economics and Statistics, 88(3):445-462, 2006.

G. Calvo. Staggered prices in a utility-maximizing framework. Journal of Monetary Economics, 12(3):383-398, 1983.

J. M. Campa and L. S. Goldberg. Exchange rate pass-through into import prices. The Review of Economics and Statistics, 87(4):679-690, 2005.

V. V. Chari, P. J. Kehoe, and E. R. McGrattan. Can sticky price models generate volatile and persistent real exchange rates? Review of Economics Studies, 69(3):533-563, 2002.

L. J. Christiano, M. Eichenbaum, and C. L. Evans. Monetary policy shocks: What have we learned and to what end? In J. B. Taylor, editor, Handbook of Macroeconomics, pages 319-347. Elsevier B.V., 1999.

L. J. Christiano, M. Eichenbaum, and C. L. Evans. Nominal rigidities and the dynamic effects of a shock to monetary policy. Journal of Political Economy, 113(1):1-45, 2005.

R. Clarida and J. Gali. Sources of real exchange-rate fluctuations: How important are nominal shocks? Carnegie-Rochester Conference Series on Public Policy, 41:1-56, 1994. 
R. Clarida, J. Galí, and M. Gertler. Monetary policy rules and macroeconomic stability: Evidence and some theory. Quarterly Journal of Economics, 115(1):147-180, February 2000.

R. Clarida, J. Galí, and M. Gertler. Optimal monetary policy in open versus closed economies: an integrated approach. American Economic Review, 91(2):248-252, 2001.

G. Corsetti and L. Dedola. A macroeconomic model of international price discrimination. Journal of International Economics, 67(1):129-155, 2005.

G. Corsetti and P. Pesenti. International dimensions of optimal monetary policy. Journal of Monetary Economics, 52(2):281-305, 2005.

D. O. Cushman and T. Zha. Identifying monetary policy in a small open economy under flexible exchange rates. Journal of Monetary Economics, 39(3):433-448, 1997.

G. de Walque, F. Smets, and R. Wouters. An estimated two-country DSGE model for the Euro area and the US economy. mimeo, 2005.

R. Dornbusch. Exchange rates and prices. American Economic Review, 77(1):93-106, 1987.

M. Dotsey and R. G. King. Implications of state-dependent pricing for dynamic macroeconomic models. Journal of Monetary Economics, 52(1):213-242, 2005.

M. Eichenbaum and C. L. Evans. Some empirical evidence on the effects of shocks to monetary policy on exchange rates. The Quarterly Journal of Economics, 110(4):975-1009, 1995.

C. Erceg, C. Gust, and D. López-Salido. The transmission of domestic shocks in open economies. mimeo, 2007.

G. Fagan, J. Henry, and R. Mestre. An area-wide model (AWM) for the euro area. ECB Working Paper 42, 2001.

J. Faust and J. H. Rogers. Monetary policy's role in exchange rate behavior. Journal of Monetary Economics, 50(7):1403-1424, 2003.

J. Galí and T. Monacelli. Monetary policy and exchange rate volatility in a small open economy. Review of Economic Studies, 72(3):707-734, 2005.

L. Guerrieri, C. Gust, and D. López-Salido. International competition and inflation: A new keynesian perspective. International Finance Discussion Papers, 918, 2008.

C. Gust, S. Leduc, and R. J. Vigfusson. Trade integration, competition, and the decline in exchangerate pass-through. International Finance Discussion Papers, Number 864, Board of Governors of the Federal Reserve System, 2006. 
J. E. Ihrig, M. Marazzi, and A. D. Rothenberg. Exchange-rate pass-through in the G-7 countries. International Finance Discussion Papers 851, 2006.

IMF. World economic outlook database. http://www.imf.org/external/pubs/ft/weo/2007/01/data/index.aspx, 2007.

S. Kim. International transmission of U.S. monetary policy shocks: Evidence from VAR's. Journal of Monetary Economics, 48(2):339-372, 2001.

S. Kim and N. Roubini. Exchange rate anomalies in the industrial countries: A solution with a structural VAR approach. Journal of Monetary Economics, 45(3):561-586, 2000.

M. Kimball. The quantitative analytics of the basic monetarist model. Journal of Money, Credit and Banking, 27(4):1241-1277, 1995.

R. Kollmann. Monetary policy rules in the open economy: Effects on welfare and business cycles. Journal of Monetary Economics, 49(5):989-1015, 2002.

R. Kollmann. International portfolio equilibrium and the current account. CEPR Discussion Paper $5512,2006$.

T. Lubik and F. Schorfheide. A bayesian look at new open economy macroeconomics. In M. Gertler and K. Rogoff, editors, NBER Macroeconomics Annual 2005, Volume 20, pages 313-366. MIT Press, Cambridge MA, 2006.

M. Marazzi, N. Sheets, R. Vigfusson, J. Faust, J. Gagnon, J. Marquez, R. Martin, T. Reeve, and J. Rogers. Exchange rate pass-through to U.S. import prices: Some new evidence. International Finance Discussion Papers 833, 2005.

A. Meier and G. J. Müller. Fleshing out the monetary transmission mechanism: Output composition and the role of financial frictions. Journal of Money, Credit and Banking, 38:2099-2134, 2006.

F. S. Mishkin. Globalization, macroeconomic performance, and monetary policy (speech). BIS Review, 108, 2007.

E. Nakamura and J. Steinsson. Five facts about prices: A reevaluation of menu cost models. mimeo Columbia University, 2008.

M. Obstfeld and K. Rogoff. New directions for stochastic open economy models. Journal of International Economics, 50(1):117-153, 2000.

OECD. SourceOECD. http://www.sourceoecd.org/, 2007.

J. H. Rogers. Monetary shocks and real exchange rates. Journal of International Economics, 49(2): 
269-288, 1999.

J. R. Rotemberg and M. Woodford. An optimization-based econometric framework for the evaluation of monetary policy. In J. B. Taylor, editor, NBER Macroeconomics Annual, pages 297-346. Cambridge, MA.: MIT Press, 1997.

A. M. Sbordone. Globalization and inflation dynamics: the impact of increased competition. Federal Reserve Bank of New York, 2007.

A. Scholl and H. Uhlig. New evidence from the puzzles: Results from agnostic identification on monetary policy and exchange rates. Journal of International Economics, forthcoming, 2008.

F. Smets and R. Wouters. Comparing shocks and frictions in US and euro area business cycles: a Bayesian DSGE approach. Journal of Applied Econometrics, 20(2):161-183, 2005.

F. Smets and R. Wouters. Shocks and frictions in US business cycles: A bayesian DSGE approach. American Economic Review, 97:586-606, 2007.

L. E. Svensson. Open-economy inflation targeting. Journal of International Economics, 50(1):155$183,2000$.

J. L. Yellen. Monetary policy in a global environment. Speech at The Euro and the Dollar in a Globalized Economy Conference, U.C. Santa Cruz, Stanta Cruz, CA, 2006. 


\section{CFS Working Paper Series:}

\begin{tabular}{|c|c|c|}
\hline No. & Author(s) & Title \\
\hline $2008 / 28$ & $\begin{array}{l}\text { Nikolas Hautsch } \\
\text { Dieter Hess } \\
\text { Christoph Müller }\end{array}$ & $\begin{array}{l}\text { Price Adjustment to News with Uncertain } \\
\text { Precision }\end{array}$ \\
\hline $2008 / 27$ & $\begin{array}{l}\text { Francis X. Diebold } \\
\text { Canlin Li } \\
\text { Vivian Z. Yue }\end{array}$ & $\begin{array}{l}\text { Global Yield Curve Dynamics and Interactions: A } \\
\text { Dynamic Nelson-Siegel Approach }\end{array}$ \\
\hline $2008 / 26$ & $\begin{array}{l}\text { Francis X. Diebold } \\
\text { Kamil Yilmaz }\end{array}$ & $\begin{array}{l}\text { Measuring Financial Asset Return and Volatilty } \\
\text { Spillovers, with Application to Global Equity } \\
\text { Markets }\end{array}$ \\
\hline $2008 / 25$ & $\begin{array}{l}\text { Günter W. Beck } \\
\text { Volker Wieland }\end{array}$ & $\begin{array}{l}\text { Central Bank Misperceptions and the Role of } \\
\text { Money in Interest Rate Rules }\end{array}$ \\
\hline $2008 / 24$ & $\begin{array}{l}\text { Christos Koulovatianos } \\
\text { Carsten Schröder } \\
\text { Ulrich Schmidt }\end{array}$ & $\begin{array}{l}\text { Confronting the Robinson Crusoe paradigm with } \\
\text { household-size heterogeneity }\end{array}$ \\
\hline $2008 / 23$ & $\begin{array}{l}\text { Jin Cao } \\
\text { Gerhard Illing }\end{array}$ & Endogenous Systemic Liquidity Risk \\
\hline $2008 / 22$ & $\begin{array}{l}\text { Zeno Enders } \\
\text { Gernot J. Müller } \\
\text { Almut Scholl }\end{array}$ & $\begin{array}{l}\text { How do Fiscal and Technology Shocks affect Real } \\
\text { Exchange Rates? New Evidence for the United } \\
\text { States }\end{array}$ \\
\hline $2008 / 21$ & Miriam Sperl & $\begin{array}{l}\text { Quantifying the Efficiency of the Xetra LOB } \\
\text { Market. A Detailed Recipe }\end{array}$ \\
\hline $2008 / 20$ & $\begin{array}{l}\text { Maria Concetta Chiuri } \\
\text { Tullio Jappelli }\end{array}$ & $\begin{array}{l}\text { Do the elderly reduce housing equity? An } \\
\text { international comparison }\end{array}$ \\
\hline 2008/19 & Annamaria Lusardi & $\begin{array}{l}\text { Financial Literacy: An Essential Tool for Informed } \\
\text { Consumer Choice? }\end{array}$ \\
\hline
\end{tabular}

Copies of working papers can be downloaded at http://www.ifk-cfs.de 